\title{
Effectiveness of intervention with visual templates targeting tense and plural agreement in copula and auxiliary structures in school aged children with complex needs: a pilot study.
}

Laura M Tobin ${ }^{\mathrm{a}}$ and Susan H. Ebbels ${ }^{\mathrm{b}, \mathrm{c}}$

aParayhouse School, London, UK; ' ${ }^{\mathrm{b}}$ Moor House Research and Training Institute, Moor House School \& College, Oxted, UK; ' ${ }^{\circ}$ Department of Language and Cognition, University College London, UK

To cite this article: Laura M Tobin \& Susan H. Ebbels (2018): Effectiveness of intervention with visual templates targeting tense and plural agreement in copula and auxiliary structures in school-aged children with complex needs: a pilot study, Clinical Linguistics \& Phonetics, DOI:10.1080/02699206.2018.1501608

To link to this article: https://doi.org/10.1080/02699206.2018.1501608

KEYWORDS

Copula; auxiliary; tense marking; intervention; Down syndrome

CONTACT Susan H. Ebbels ebbelss@ moorhouseschool.co.uk, Moor House School \& College, Mill Lane, Hurst Green, Oxted RH8 9AQ, UK 


\begin{abstract}
This pilot study aimed to evaluate the effectiveness of a school-based intervention using visual strategies for improving accurate use of auxiliary and copula marking in singular and plural, past and present tense by students with moderate learning disability and complex needs. 11students, aged 10-14 years, in a specialist school based in UK, participated in the study. A within participants design was used which included testing at baseline, pre and post intervention to consider progress with intervention as compared with progress during a baseline period of similar length. The experimental intervention consisted of eight, bi-weekly, 20 minute sessions, over a four week period, in small groups, in a classroom setting. Half of the participants focused on the auxiliary and half on the copula, but all were tested on both. Techniques included the use of visual templates and rules (the Shape Coding ${ }^{\mathrm{TM}}$ system) to support explicit instruction. Eight participants made greater progress during the intervention term than during the baseline term and this was significant at a group level $(\mathrm{d}=0.92)$. A comparison of progress to zero was not significant during the baseline period $(\mathrm{d}=0.15)$, but was during the intervention period $(\mathrm{d}=1.07)$. Progress also appeared to generalise from the targeted to non-targeted structure. This pilot study therefore provides preliminary evidence that older students with complex needs can make progress with morphology when intervention includes explicit instruction and visual templates and that generalisation may be observed.
\end{abstract}




\section{Introduction}

Grammatical aspects of language are particularly difficult for children with language learning difficulties, especially those with Developmental Language Disorder (DLD), both in English (Bedore\& Leonard, 1998; Leonard, Eyer, Bedore, \&Grela, 1997; Rice, Tomblin, Hoffman, Richman, \& Marquis, 2004; Rice \&Wexler, 1996; Rice, Wexler, \& Hershberger, 1998) and in other languages, e.g., Spanish and German (Sanz-Torrent, Serrat, Andreu, Serra, 2008; Krok \& Leonard, 2015).

Language difficulties in children with DLD often persist into adulthood, affecting psycho-social (Clegg, Hollis, Mawhood \& Rutter, 2005) and educational outcomes (ContiRamsden, 2008), and employment prospects (Law, Rush, Schoon \& Parsons, 2009). As a result, much research has been carried out aiming to remediate their difficulties and improve long term outcomes. Other populations also have language learning deficits, including individuals with Down Syndrome (DS) (Laws \& Bishop, 2003; Sepulveda, Lopez-Villasenor, \& Heinze, 2013), Hearing Impairment (HI) (Bol \& Kuiken, 1990; Moeller, Tomblin, Yoshinaga-Itano, Connor \& Jerger, 2007), and Attention Deficit Hyperactivity Disorder (ADHD) (Cohen et al. 2000; Geurts \& Embrechts, 2008).These individuals, who present with these concurrent needs, are also at risk of loweremployment rates (WHO, 2011); and psychosocial functioning (Netten et al. 2015; Laugen, Jacobsen, Rieffe, \&Wichstrøm, 2016) possibly to a greater extent than those with DLD due to increased complexity of needs . Individuals who present with a range of language and learning needs (often described as 'complex') form a large proportion of Speech and Language Therapists'/Pathologists' (SLT/P) caseloads. However, despite similar difficulties and long term outcomes, limited research exists regarding interventions with these clients. 
The National Health Service (NHS), the health care system in the United Kingdom (UK), defines those with 'complex needs' as individuals who have been diagnosed with an illness, disability or sensory impairment and need a lot of additional support on a daily basis, (http://www.nhs.co.uk). Finding a prevalence figure to represent language impairment in the cohort described as 'complex' is a challenge. There are currently 1.5 million people in the U.K., around 3\% of the population, with a learning disability (http://www.mencap.org.uk/), and clinical experience shows that the majority of individuals with a learning disability have Speech, Language and Communication Needs (SLCN). At a time when resources are being cut, speech and language interventions need to show effective outcomes based on evidence. Furthermore, SLT/Ps need to consider the evidence available relating to more specific populations.

Limited evidence exists regarding the effectiveness of speech and language intervention programmes for more specific populations. Burgoyne et al. (2012), found that a reading and language intervention programme was effective in improving reading skills and expressive vocabulary of school aged children with DS, but improvements did not generalise to other areas, namely grammar. Sepulveda et al. (2013) found that individuals with DS made improvements in their language use following an intervention programme focusing specifically on morph- syntactic structures. For individuals with hearing impairment, much research focuses on early intervention and long term outcomes (Carney \& Moeller, 1998) whereas evidence on effectiveness of specific language intervention programmes within this population is, once again, limited. Moreover, there are no current studies known to the authors that include a cohort of students who present with a range of diagnoses and additional learning needs. This gap in the research is likely influenced by the challenge in controlling variables within populations that present with varied and complex language and learning needs. However, SLT/P caseloads include students who have learning disabilities, including 
diagnoses of DS, many of whom may have associated hearing impairment (HI), and other sensory needs, and/or English as an Additional Language (EAL). These varied individuals require evidence based intervention that is tailored to meet their particular strengths and needs. It could be argued these children with more persistent difficulties, are most in need of intervention, and yet limited research evidence exists.

The variability in the presentations of children with language and learning difficulties make it very challenging to control variability within studies and hence strengthen the reliability. Sepulveda et al. (2013), in reference to individuals with DS, noted that this population alone constitutes a very heterogeneous collective. However, this variability does not negate the need for more research in the area.

Children and adults with DS have deficits in verbal working memory which is related to poor expressive language outcomes, both in English (Byrne, Buckley, MacDonald, \& Bird, 1995; Hesketh \& Chapman, 1998; Jarrold, Baddeley, \& Phillips, 2002) and in other languages, e.g., Japanese and Italian (Kanno\& Ikeda, 2002; Vicari, Bellucci\&Carlesimo, 2000; Volterra, Caselli, Capirci, Tonucci\&Vicari, 2003).

In contrast, many individuals with DS have been shown to present with relatively stronger visuo-spatial skills (Wang \&Bellugi, 1994;Jarrold \&Baddeley, 1997; Jarrold, Baddeley \& Hewes, 1999; Klein \& Mervis, 1999; Fidler, 2005; Duarte, Covre, Braga \& de Macedo, 2011).

As a result many special need educators and allied health professionals working with individuals with DS (and indeed other children with complex needs) aim to maximise this visual strength and employ multimodal teaching strategies.

There is growing evidence to support the effectiveness of the use of multi-modal approaches to teaching grammatical structures to children with DLD (Zwitserlood, Wijnen, 
van Weerdenburg \&Verhoeven, 2015; Ebbels, 2007; Ebbels \& van der Lely, 2001; Ebbels, van der Lely \& Dockrell, 2007; Ebbels, Maric, Murphy \& Turner, 2014) and we hypothesise such approachescould support acquisition of grammatical structures for individuals with more complex needs, including those with DS. The Shape Coding ${ }^{\mathrm{TM}}$ system uses shapes, colours and arrows to make the grammatical rules of English explicit and, of particular relevance to this study, uses lines and arrows as a visual prompt to support a learner's acquisition of plural and tense agreements. The rationale for metalinguistic intervention is based on the theory that many children with DLD have difficulties learning grammar implicitly and benefit from explicit teaching of grammatical rules (e.g., Ebbels et al. 2014). This hypothesis is in line with results suggesting that procedural memory is impaired in children with DLD (Lum, Conti-Ramsden, Page \& Ullman,2012; Ullman \& Pierpont, 2005), whereas declarative memory, which supports explicit learning, is a relative strength that can support the acquisition of grammatical rules (Ullman \& Pierpont, 2005). Previous studies however, involved individuals with DLD and the effectiveness of such visual approaches has not been tested in other populations.

Syntactic comprehension and the acquisition of morphology are areas of particular difficulty for English-speaking individuals with DS (Law \& Bishop, 2003; Martin, Klusek, Estigarribia\& Roberts, 2009; Chapman, 2006; Eadie, Fey, Douglas, \& Parsons, 2002), including the acquisition and rules pertaining to auxiliary and copula forms (Rutter\& Buckley, 1994; Law \& Bishop, 2003). Similar difficulties in morpho-syntactic structures have been found in Italian children with DS (Vicari, Caselli, Tonucci, 2000; Caselli, Monaco, Trasciani, Vicari, 2008).

This is also true of other populations, for example, Elfenbein, Hardin-Jones \& Davis (1994) found the most frequent errors of school-aged students with hearing impairment 
related to complex syntax and verb structures including omission of copulas, auxiliary and modal verbs.

Several studies have investigated the effectiveness of intervention for the auxiliary and generalization from this to the copula in children with DLD (Leonard, 1974; Hegde, 1980; Tyler, Lewis, Haskill \& Paul, 2003). These all found increases in both the targeted auxiliary and the non-targeted copula. However, no intervention studies have investigated this area in other, more 'complex' populations.

\section{Summary}

There is increasing evidence demonstrating the effectiveness of multimodal approaches in supporting the development of grammatical structures for children with DLD. However, there remains little evidence to support specific language programmes including the use of visuals for more complex populations of children despite a relative strength in their visual processing skills. This study aims to begin to address this gap in the evidence by asking: Do students with a range of complex learning needs, receiving an intervention programme, which includes the use of the Shape Coding ${ }^{\mathrm{TM}}$ system, targeting plural and tense marking in the copula or the auxiliary form of the verb 'to be', show more progress during an intervention period than during a preceding baseline period? And furthermore, does progress generalise to the untreated verb type?

\section{Method}

\section{Study Design}

This study used a within participants single baseline design whereby a baseline assessment was administered followed by a pre-intervention assessment four weeks later. Intervention was then delivered over a four week period and then a post-intervention assessment 
administered. All participants were tested on production of both copulas and auxiliaries, but half the participants received a treatment programme focusing only on the auxiliary form of the verb 'to be' (e.g., he iseating) whilst the other half focused only on the copula form (e.g., he $\underline{i s}$ hungry). During the baseline period the participants received their regular speech and language input, focusing on phonological awareness, reading comprehension, vocabulary development and narrative skills, but this input did not focus on morpho-syntax.

\section{Participants}

11 students with moderate learning disabilities and complex needs (aged 10-14 years) attending a specialist education provision in the UK participated in the study. These students were referred to the programme by their SLT/P who identified a need for support in morphosyntax and specifically for producing the correct form of the auxiliary and copula in sentences. The participants presented with a range of complex needs, including, bi-lateral HI, EAL and diagnoses of DS. Furthermore, at the time of the intervention, the students' statements of special educational need described them as presenting with a moderate learning disability, with a primary need in speech, language and communication, see Table 1. 
Table1: Participant overview

\begin{tabular}{|c|c|c|c|c|c|c|c|}
\hline Participant & Age & $\begin{array}{l}\text { TROG } \\
\text { Raw score } \\
/ 80\end{array}$ & Diagnosis & $\mathrm{HI}$ & EAL & Other & Target \\
\hline 1 & 10 & 11 & DS & $*$ & & & Aux \\
\hline 2 & 11 & 20 & DS & $*$ & & & Aux \\
\hline 3 & 11 & 23 & DS & & $*$ & ADHD & Aux \\
\hline 4 & 11 & 4 & DS & & & & Aux \\
\hline 5 & 14 & 15 & DS & & & & Aux \\
\hline 6 & 14 & 20 & DS & & & & Cop \\
\hline 7 & 12 & 43 & GDD & & $*$ & & Cop \\
\hline 8 & 14 & 22 & GDD & $*$ & $*$ & & Cop \\
\hline 9 & 13 & 66 & GDD & & $*$ & & Cop \\
\hline 10 & 11 & 32 & GDD & & $*$ & & Cop \\
\hline 11 & 11 & 66 & GDD & & $*$ & & Cop \\
\hline \multicolumn{8}{|l|}{ Key: } \\
\hline$\overline{\mathrm{DS}}$ & \multicolumn{7}{|c|}{ Down syndrome } \\
\hline GDD & \multicolumn{7}{|c|}{ Global developmental delay } \\
\hline $\mathrm{HI}$ & \multicolumn{7}{|c|}{ Hearing impairment } \\
\hline EAL & \multicolumn{7}{|c|}{ English as an Additional Language } \\
\hline Aux & \multicolumn{7}{|c|}{ Auxiliary verb group } \\
\hline Cop & \multicolumn{7}{|c|}{ Copula verb group } \\
\hline
\end{tabular}

In line with the school's policy, the students were in class groups based on their language comprehension level and the existence of a suitable social peer group. The school's model involved key teachers and speech and language therapists working collaboratively. Therefore, therapy targets were often related to classroom and literacy goals related to the 
curriculum. The decision regarding whether each participant focused on auxiliaries or copulas was dependent on the ease of incorporating these concurrent targets. Increasing use of verbs and extending sentence length was an ongoing target for many of the students with DS whereas targets for the other students included description of characters in narratives. For these latter students, focusing on copula (plus adjective) was more closely related to their curriculum targets, whereas those with sentence length targets could focus on either auxiliaries or copulas. To even out the numbers in the two groups, five out of six of the students with DS therefore targeted the auxiliary forms in their intervention.

\section{Measurements}

For children with complex needs and EAL, bespoke assessment is often the main tool to evaluate this group's communication needs as standardised assessments are not normed on this complex population. In addition, there are few tests that have specific test items that measure tense and plural agreement in structures including the auxiliary and copula forms; for example, the CELF 4 (Semel, Wiig, Hannan \& Secord, 2006) includes only one item on tense and plural marking of an auxiliary form. Therefore, for the purpose of this study a bespoke assessment was devised (See Appendix A for a list of the instructions, prompts and target sentences).

The participants were shown a series of pictures and videos. The picture stimuli depicted scenes that required expressing the copula with an adjective or prepositional phrase e.g. the apple is red, the ball is on the table. The video stimuli showed people carrying out basic actions e.g. the man is sleeping. For each stimulus the student was asked a question that was designed to elicit either the copula or the auxiliary form of the verb 'to be' for example: Tell me about the man on the video? This structure was used in order to avoid priming the participants with an auxiliary in the question, e.g. what is the man doing? In order to elicit the 
past progressive a probing question would follow the present progressive item, i.e. the lady is sleeping....“ can you remember the man?” or for copula forms: The hat was on the table.... "What about the banana and lemon?" Trial and example items of structures were provided at the beginning of the assessment. If the participant produced a single word response the therapist followed a prompting hierarchy: the first prompt was 'Give me a full sentence' and if this did not elicit the target structure the SLT/P provided a 'lead-in phrase' i.e. 'The man...' The participants' responses were then transcribed live on to recording forms.

The assessment was piloted on an older student in the same provision and on a typically developing child to evaluate its effectiveness in eliciting the auxiliary/copula structures. The prompting hierarchy was included following piloting to increase the standardisation in administration among the therapists carrying out the testing. The assessment was administered to the students using a tablet; the reasoning was two-fold. Firstly, it was considered a motivating and engaging tool for the students. Secondly, it was important to have 'live' videos to represent an action in progressive forms in order to create a realistic stimulus to elicit the desired verb structure.

\section{Intervention Method}

The intervention programme included the Shape Coding ${ }^{\mathrm{TM}}$ system (Ebbels, 2007), a visual approach that employs lines and arrows to support the learning of plural and tense agreements. In the Shape Coding system, subjects are placed in ovals and both auxiliaries and copulas in diamonds (to highlight their similarities in both subject-verb agreement and also movement to before the oval in questions). Singular/plural agreement is shown with single and double lines on the noun in the subject position and under the auxiliary/copula in the diamond (see Figure 1). The number of lines under the noun(s) has to match the number of 
lines in the diamond. If there are two entities in the subject oval (and hence two red lines in total, e.g., one under boy and one under girl) a double line is required under the verb. This can help prevent errors such as "the boy and the girl is eating" as the single line under "is" doesn't match the two red lines in the oval.

Verb tenses are shown in the Shape Coding system using arrows for tensed verbs (present tense in the middle and past tense at the left hand end). These can go either on the main verb or on the auxiliary/copula. They match a similar arrow (to indicate present versus past time) shown on the time adverbial (in a triangle, representing when). Singular/plural marking and tense marking can also be combined. The combination is shown in Figure 1 for auxiliaries and copulas, but when the focus is just on singular/plural agreement, the arrows can be omitted and when the focus is just on tense, the double lines can be omitted.

The intervention was delivered by the participants' own SLT/P(four SLT/Ps in total) as part of their normal intervention package. Participants were seen twice a week, for 20 minute sessions, for 4 consecutive weeks ( 8 sessions, 4 hours in total) in groups of 2-3.

The intervention sequence was devised by the first author and a sequence of goals and activities were provided to the SLT/Ps. This consisted of a series of 12 steps, the first six focusing on use of singular and plural auxiliary or copula is and are and the second six introducing the past tense versions was and were, see Appendix B for details of the intervention steps. A resource pack was provided which included enlarged coloured lines and arrows for use by the students during the sessions. In the copula groups, photos representing adjectives and prepositional phrases were provided. For the groups targeting the auxiliary, videos of familiar people and actions were used; the people and actions differed from those in the assessment. 
Figure 1: Singular/plural agreement plus verb tenses on auxiliaries and copulas in the Shape Coding ${ }^{T M}$ system.
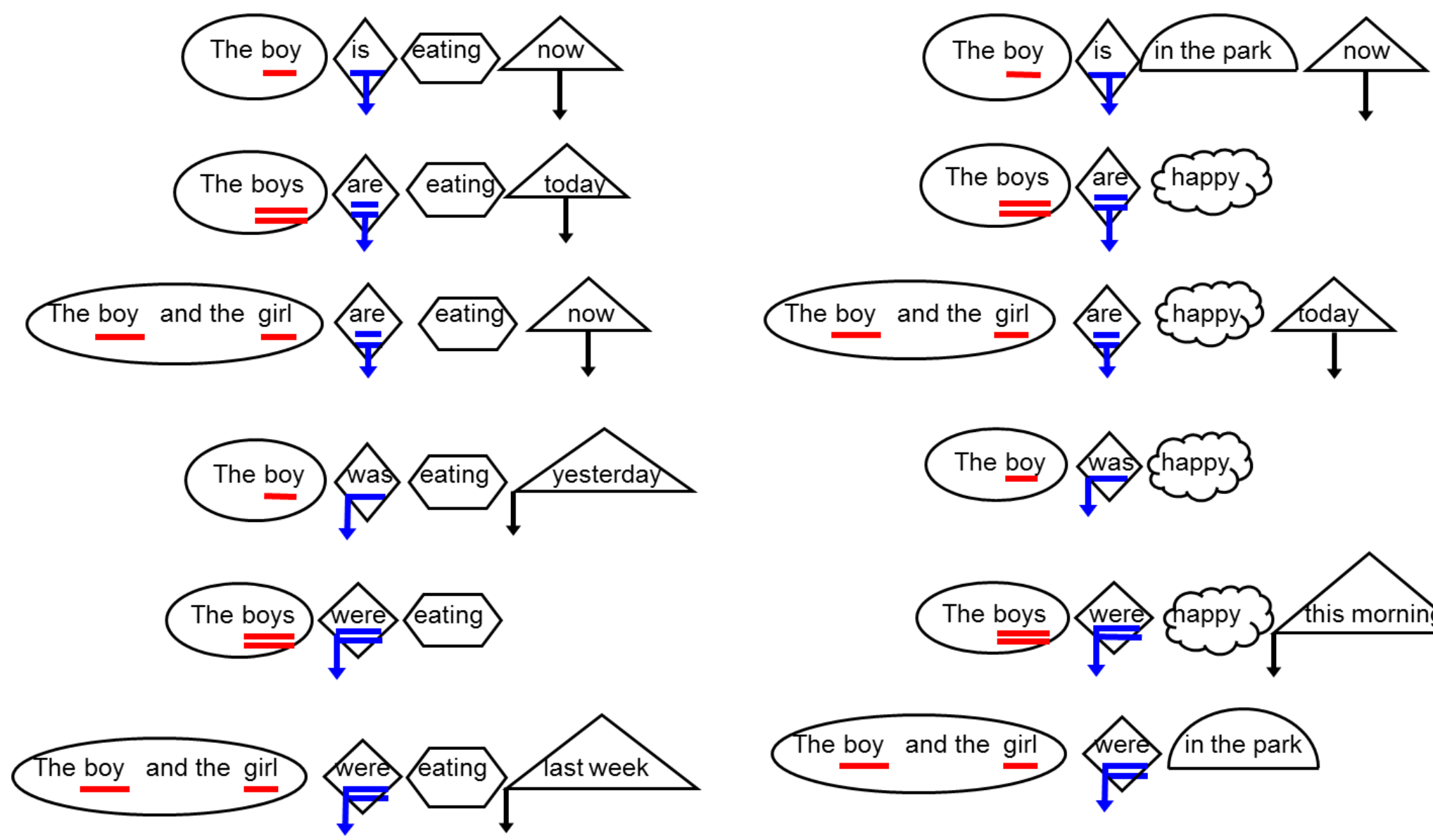
Explicit teaching was employed to teach agreement using the visual cues of lines, for example the SLT/P would say: "the boy is one person, he gets a red line, and the boys are two people, so they get two red lines". This would be followed by the students matching the form of the verb 'is' (which would be underlined with one blue line) or 'are' (which would be underlined with two blue lines) with the appropriate subject. For those students who progressed to tense marking, they would learn to match time adverbials (underlined with an arrow indicating the past) e.g. Yesterday, last week etc. with the past tense of the verb 'to be' i.e. was or were (underlined by an arrow indicating the past).

The copula and auxiliary interventions were provided as part of the participants' regular intervention plan which includes joint planning of core lessons such as English and Maths as well as consultation on language levels and vocabulary in other subjects, although this varies with the language needs of the child. Some participants received individual intervention during the same period as their copula/auxiliary intervention which focused on other areas of communication including articulation, phonological awareness, reading comprehension and language concepts.

\section{Attendance and Treatment Fidelity}

Attendance and treatment fidelity were monitored informally by the first author. The SLT/Ps kept attendance records and notes on sessions and reported to the first author regularly on the progress of the treatment plan. In the event that a student missed a session, SLT/Ps were able to offer a 'catch up' session to ensure they received the same amount of therapy as their fellow participants. All participants received eight, 20 minute, sessions over four weeks.

The SLT/Ps delivering the intervention reported that they followed the basic plans

outlined in Appendix B. The SLT/Ps also reported using varying levels of Makaton ${ }^{\mathrm{TM}}$ signing 
throughout their sessions. The SLT/Ps used their own clinical judgment as to how quickly the students progressed through the steps. The intervention ended after eight sessions regardless of the step which participants had reached. Due to the participants' varying needs and abilities they did not all progress through all the steps of the intervention plan. The five participants in the auxiliary group progressed to Step 5 in their eight sessions. Two participants in the copula groups progressed to Step 11 and the remaining four participants completed the programme in full.

\section{Results}

Figure 2 shows the mean proportion correct for copulas and auxiliaries at baseline, preintervention and post-intervention for the two groups of participants.

Figure 2: mean proportion correct (error bars show 1 standard error) at each time point.

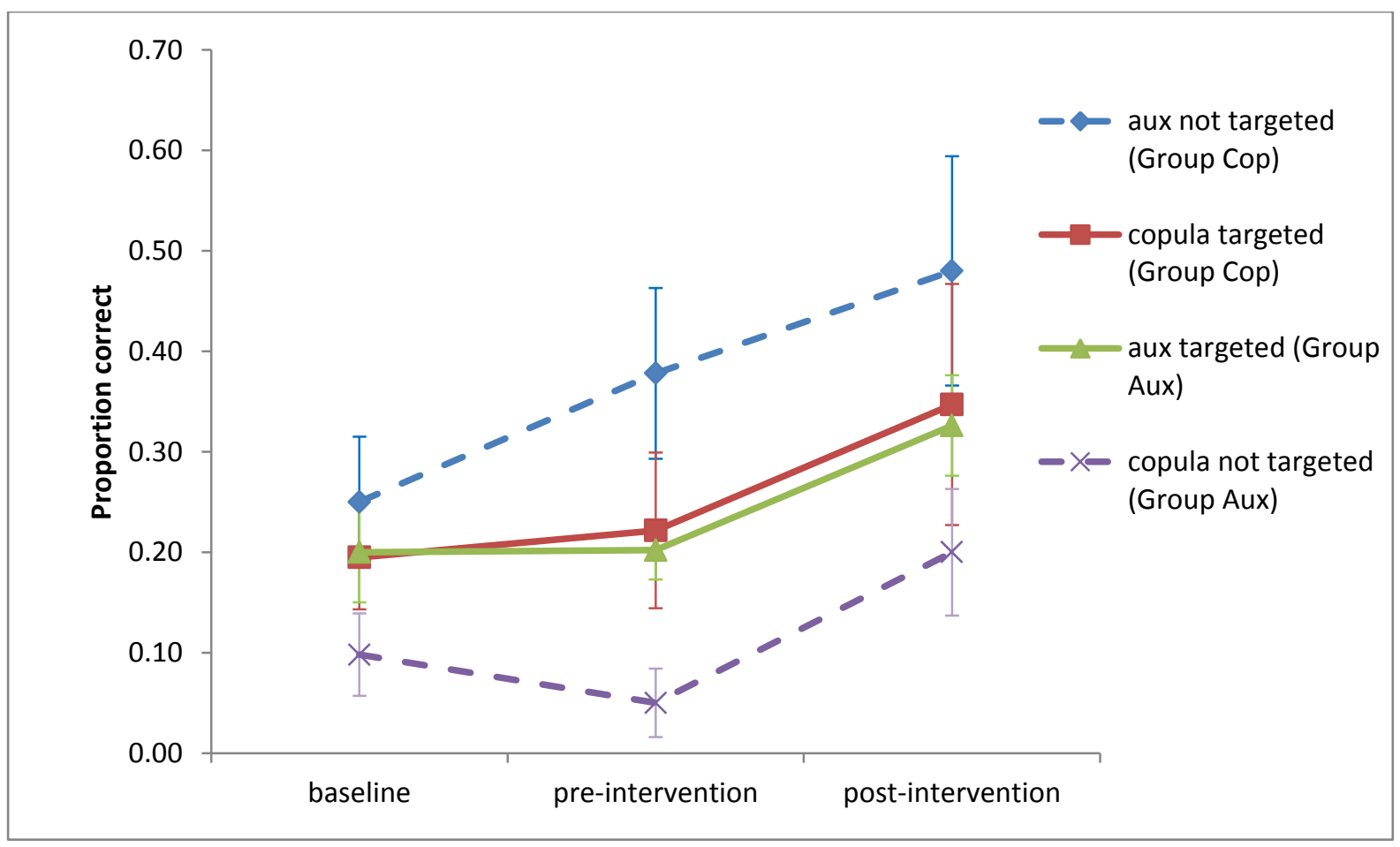


Any change during the baseline period could be due to non-intervention-specific factors such as maturation, practice or placebo effects, or regression to the mean. So, the comparison of interest is: change during the baseline term (pre-intervention minus baseline score) versus change during the intervention term (post-intervention minus pre-intervention), as this can reveal any additional progress during the intervention term which cannot be attributed to those non-specific factors which would be likely to affect both the baseline and intervention periods. The changes for both groups of participants combined in the overall proportion correct (copula and auxiliary combined) and copula alone and auxiliary alone are shown in Table 2.

Table 2: Mean (SD), range of change, significance ( $p)$ and effect size $(d)$ in overall proportion correct (copula and auxiliary combined), copula alone, auxiliary alone

\begin{tabular}{lllllc}
\hline & & Mean $(S D)$ & Range & p-value & d-value \\
\hline Aux and cop & Change during baseline & $0.02(0.13)$ & -0.20 to 0.35 & 0.59 & 0.15 \\
combined & Change with intervention & $0.13(0.12)$ & 0.00 to 0.35 & 0.01 & 1.08 \\
Copula & Change during baseline & $-0.007(0.12)$ & -0.25 to 0.25 & 0.89 & 0.06 \\
& Change with intervention & $0.14(0.14)$ & 0.00 to 0.42 & 0.01 & 1.00 \\
& & & & & \\
Auxiliary & Change during baseline & $0.07(0.17)$ & -0.12 to 0.50 & 0.06 & 0.41 \\
& Change with intervention & $0.11(0.10)$ & 0.00 to 0.25 & 0.02 & 1.10 \\
\hline
\end{tabular}

These change scores have a severely non-normal distribution $(p<.003)$ and thus we used the non-parametric tests for all analyses. A Wilcoxon matched pairs Signed-Ranks test showed the change with intervention(auxiliary and copula combined) was significantly 
greater than change during the baseline period, $Z=47.0, p=0.039, d=0.92$ where eight of the eleven participants showed greater change overall with intervention than during the baseline period. Splitting the results into auxiliaries and copulas showed a significant difference between the intervention and baseline terms for the copula, $Z=5.0, p=0.02, d=1.18$ (where nine participants showed greater progress during the intervention term), but not for the auxiliary, $Z=16.5, p=0.83, d=0.30$.

In order to compare whether the progress made during each of the baseline and intervention terms on each area was significantly greater than zero, we carried out onesample Wilcoxon Signed-Ranks tests. The results ( $p$-values and $d$-values) are shown in Table 2. In each case, any progress made during the baseline period was not significant, but progress during the intervention term was, with large effect sizes $(d \geq 1.0)$.

Due to the small number of participants it wasn't possible to fully investigate the generalization effects from the targeting of copulas versus auxiliaries by splitting the participants into two smaller groups. However, Figure 2 indicates that both groups made similar progress with intervention on both the targeted and non-targeted items, regardless of whether they targeted the auxiliary or copula. To investigate this, we carried out a Wilcoxon matched pairs Signed-Ranks test for all participants combined, comparing change during the intervention term on targeted (Mean: 0.12, SD: 0.11) versus non-targeted items (Mean: 0.12, $\mathrm{SD}$ : 0.14). This showed no significant difference, $Z=13.5, p=0.93, d=0.00$, indicating generalization from the targeted to non-targeted items during the intervention term.

\section{Discussion}

The aim of this study was to evaluate the effectiveness of an intervention programme designed to target tense and plural marking for the verb 'to be', in a special school setting. 
The intervention programme included the use of the Shape Coding ${ }^{\mathrm{TM}}$ system. Within the Shape Coding system, the clinician employs the use of lines and arrows as a visual prompt to support a learner's acquisition of plural and tense agreements.

The results obtained indicate that the participants, with moderate learning disabilities and complex needs, showed significantly more progress during an intervention period, than during a preceding baseline period, with a large effect size. Thus, the outcomes cannot be attributed to other non-intervention-specific factors such as the school environment, developmental progress, or regression to the mean. Therefore, the results of this pilot study provide preliminary evidence of the effectiveness of using such an approach with older children with a range of learning disabilities and complex needs, including those with HI, DS, EAL and ADHD. The results of this study add to existing research that demonstrates the effectiveness of intervention that includes use of the Shape Coding system, but is the first study to show positive outcomes with a more complex cohort.

In addition, our results also indicate that progress in both groups generalised to the non-targeted verb type. For instance, participants who targeted plural and tense marking with the copula structure: e.g., "The apples are red" carried over their learning to structures including the auxiliary e.g., "the boys are playing". This indicates that the participants did not have to target the verb type 'to be' in both forms in order to make progress in both forms, an outcome similar to previous research which showed generalization from the auxiliary to copula (Leonard, 1974; Hegde, 1980; Tyler et al. 2003). This study adds to previous research in indicating that generalization can also occur from copula to auxiliary. This finding has important implications for clinical practice, namely that it may be possible to target one area and that improved skills may generalise to untargeted structures, thus meeting language goals more efficiently. 
The results of this study support previous research that demonstrates the effectiveness of visual supports for students with learning disabilities, in particular students with DS (Fidler, 2005; Wang \&Bellugi, 1994). In addition, this study supports and adds to current research on the effectiveness of Shape Coding techniques to develop understanding and expression of syntactic structures (Ebbels\& van der Lely 2001, Ebbels, 2007; Ebbels et al. 2007, 2014).The Shape Coding system was designed for the grammar of English. However, it could be adapted for other languages in line with their grammatical systems. Considering there are cross-linguistic similarities in DS language and learning profiles, a visuospatial based intervention for teaching grammatical structures may be effective for other languages. However, this remains to be tested.

This research was undertaken as a pilot study, carried out with a cohort of students that is often excluded from research studies because of the complexity of their presentations and difficulty controlling all the variables. This aspect of participant selection, although understandable, limits our evidence base for interventions with a large proportion of SLT/P caseloads. In the interest of providing a 'robust' evidence base we are not reflecting a 'real' picture. Also, it could be argued that we, as clinicians, are not offering equal opportunities to individuals who have complex learning needs by not pursuing research in the area because they are considered 'ineligible' for inclusion in studies.

\section{$\underline{\text { Implications for clinical practice }}$}

There is increasing evidence for interventions targeting grammar in school-aged children with DLD, but not for those with more complex needs. The evidence base needs to involve children with a range of profiles that reflect typical SLT/P caseloads. Research needs to be embedded in, and reflective of real clinical practice. 
Our results indicated progress in both groups, suggesting that individuals of all abilities, age, and with varied presentations can make some level of progress. Our study also indicates that small group intervention (2-3 students in a group) can be an effective form of service delivery.

\section{$\underline{\text { Limitations \& Further directions }}$}

This was an effectiveness study and therefore it was difficult to control all variables, and owing to timetabling and staffing, random allocation to groups did not occur. Due to the small number of participants, it was not possible to consider the effects of participant variables such as age, cognitive ability, EAL and other diagnoses on progress and outcomes. Therefore, more research needs to be carried out evaluating the effectiveness of similar interventions, with a greater number of participants. Further research could investigate whether a similar visual based system could support morpho-syntactic structures in other languages and indeed, for children who speak more than one language, whether learning could generalize to other languages spoken.

Although we found progress in tense and plural marking with a large effect size, the students still had difficulties with these structures even after intervention. Therefore further research could investigate the impact of intervention of a longer duration than the four hours in this study.

This study was small scale and based in one school. It cannot be assumed that the results will generalise to other groups in different settings. Therefore larger studies in different settings are needed. However, this is the first study evaluating the effectiveness of an intervention programme that included the use of the Shape Coding ${ }^{\mathrm{TM}}$ system with a more 'complex' cohort. 


\section{Conclusion}

This pilot study demonstrated the effectiveness of an intervention programme designed to target tense and plural marking with the verb 'to be' with students with a range of learning needs in a real clinical context. The participants in this study are representative of complex caseloads that do not include exclusionary criteria. Further, larger-scale research needs to be carried out in order to determine the generalisability of these results to other populations and environments.

Acknowledgements

The authors thank the SLT/Ps who were involved in the assessments and the intervention programme (Amber Hawkins, Sarah McGowan and Emma Pomroy). This study was funded by Parayhouse School [charity number 1090757], where the first author was employed at the time of the study.We also thank the families who participated in this research.

References

Bedore, L., \&Leonard, L.B. (1998). Specific language impairment and grammatical morphology: A discriminant function analysis. Journal of Speech, Language, and Hearing Research, 41, 1185-1192.

Bishop, D. (2003). Test of Receptive Grammar: TROG-2. London: Pearson Assessment (Harcourt Assessment). 
Bol, G. \&Kuiken, F. (1990). Grammatical analysis of developmental language disorders: a study of the morpho-syntax of children with specific language disorders, with hearing impairment and with Down's syndrome. Clinical Linguistics and Phonetics, 4, 77-86.

Burgoyne, K., Duff, F.J., Clarke, P.J., Buckley, S., Snowling, M.J. \&Hulme, C. (2012). 'Efficacy of a reading and language intervention for children with Down Syndrome: a randomized controlled trial'. Journal of Child Psychology and Psychiatry, 53(10), 1044-53.

Byrne, A., Buckley, S., MacDonald, J., \& Bird, G. (1995). Investigating the literacy, language, and memory skills of children with Downssyndrome. DownSyndrome: Research and Practice, 3, 53-58.

Carney, A. E., \& Moeller, M. P. (1998). Treatment efficacy: Hearing loss in children. Journal of Speech, Language, and Hearing Research, 41(1) 61-84.

Caselli, M. C., Monaco, L., Trasciani, M. \& Vicari, S. (2008). Language in Italian children with Down syndrome and with specific language impairment. Neuropsychology, 22, 27-35.

Chapman, R. (2006). Language learning in Down syndrome: The speech and language profile compared to adolescents with cognitive impairment of unknown origin. Down Syndrome Research and Practice, 10, 61-66.

Clegg, J., Hollis, C., Mawhood, L., \&Rutter, M. (2005). Developmental language disorders a follow-up in later adult life: Cognitive, language and psychosocial outcomes. Journal of Child Psychology and Psychiatry, 46, 128-149.

Cohen, N. J., Vallance, D. D., Barwick, M., Im, N., Menna, R., Horodezky, N. B., \& Isaacson, L. (2000). The interface between ADHD and language impairment: an examination of language, achievement, and cognitive processing. Journal of Child Psychology and Psychiatry, 41(3), 353-362. 
Conti-Ramsden, G. (2008). Heterogeneity of specific language impairment in adolescent outcomes. In C. F. Norbury, J. B. Tomblin, \& D. V. M. Bishop (Eds.), Understanding developmental language disorders: From theory to practice (pp. 117-130). Hove: Psychological Press.

Duarte, C. P., Covre, P., Braga, A. C., de Macedo, E.C. (2011). Visuospatial support for verbal short-term memory in individuals with Down syndrome. Research in Developmental Disabilities, 32, 1918-1923.

Eadie, P. A., Fey, M. E., Douglas, J. M., \& Parsons, C. L. (2002).Profiles of grammatical morphology and sentence imitation in children with specific language impairment and Down syndrome. Journal of Speech, Language, and Hearing Research, 45, 720-732.

Ebbels, S. H. (2007) Teaching grammar to school-aged children with specific language impairment using Shape Coding. Child Language Teaching and Therapy, 23, 67-93.

Ebbels, S. (2014). Effectiveness of intervention for grammar in school-aged children with primary language impairments: A review of the evidence. Child Language Teaching and Therapy, 30, 7-40.

Ebbels, S. H., Maric, N., Murphy, A., \& Turner, G. (2014).Improving comprehension in adolescents with severe receptive language impairments: a randomized control trial of intervention for coordinating conjunctions. International Journal of Language \& Communication Disorders, 49(1), 30-48.

Ebbels, S. H., van der Lely, H. K. J., \&Dockrell, J. E. (2007). Intervention for verb argument structure in children with persistent SLI: a randomized control trial. Journal of Speech Language and Hearing Research, 50, 1330-1349. 
Ebbels, S., \& van der Lely, H. (2001). Meta-syntactic therapy using visual coding for children with severe persistent SLI.International Journal of Language \& Communication Disorders, 36, 345-350.

Elfenbein, J. L., Hardin-Jones, M. A., \& Davis, J. M. (1994).Oral communication skills of children who are hard of hearing.Journal of Speech and Hearing Research, 37, 216 -226.

Fidler, D. J. (2005). The emerging Down syndrome behavioral phenotype in early childhood: Implications for practice. Infants and Young Children, 18, 86-103.

Geurts, H. M. \&Embrechts, M. (2008).Language profiles in ASD, SLI, and ADHD. Journal of Autism and Developmental Disorders, 38 (10), 1931-1943.

Hegde, M. (1980).An experimental-clinical analysis of grammatical and behavioral distinctions between verbal auxiliary and copula. Journal of Speech and Hearing Research, $23,864-877$.

Hesketh, L. J., \& Chapman, R. S. (1998).Verb use by individuals with Down syndrome. American Journal on Mental Retardation, 103, 288-304.

Jarrold, C., \&Baddeley, A. D. (1997).Short-term memory for verbal and visuo-spatial information in Downssyndrome. Cognitive Neuropsychiatry, 2, 101-122.

Jarrold, C., Baddeley, A. D., \&Hewes, A. K. (1999).Genetically dissociated components of working memory: Evidence from Downs and Williams syndrome.Neuropsychologia, 37, $637-651$.

Jarrold, C., Baddeley, A. D., \& Phillips, C. E. (2002). Verbal short-term memory in Down syndrome: A problem of memory, audition, or speech? Journal of Speech, Language, and Hearing Research, 45, 531-544. 
Kanno, K. \& Ikeda, Y. (2002) Word- length effect in verbal short- term memory in individuals with Down's syndrome. Journal of Intellectual Disability Research, 46 (8), 613618.

Klein, B.P. \&Mervis, C. B. (1999).Contrasting patterns of cognitive abilities of 9- and 10year-olds with Williams syndrome or Down syndrome. Developmental Neuropsychology, $16,177-196$.

Krok, W.C. \& Leonard, L. B. (2015). Past tense production in children with and without specific language impairment across Germanic languages: A meta-analysis. Journal of Speech, Language and Hearing Research, 58 (4), 1326-1340.

Laugen, N. J., Jacobsen, K. H., Rieffe, C., \&Wichstrøm, L. (2016).Predictors of psychosocial outcomes in hard of hearing preschool children.Journal of Deaf Studies and Deaf Education, 2016, 259-267.

Law, J., Rush, R., Schoon, I. \& Parsons, S. (2009). Modeling developmental language difficulties from school entry into adulthood: literacy, mental health, and employment outcomes. Journal of Speech Language and Hearing Research, 52, 1401-1416.

Laws, G., \& Bishop, D.V.M. (2003).A comparison of language abilities in adolescents with Down syndrome and children with specific language impairment. Journal of Speech, Language, and Hearing Research, 46, 1324-1339.

Leonard, L. (1974). A preliminary view of generalization in language training. Journal of Speech and Hearing Disorders, 39, 429-436.

Leonard, L., Eyer, J., Bedore, L., \&Grela, B. (1997). Three accounts of the grammatical morpheme difficulties of English-speaking children with specific language impairment. Journal of Speech, Language, and Hearing Research, 40, 741-753. 
Lum, J.A., Conti-Ramsden, G., Page D., Ullman, M.T. (2012). Working, declarative and procedural memory in Specific Language Impairment. Cortex, 38 (9), 1138-54.

Martin, G.E., Klusek, J., Estigarriba, B. \& Roberts, J.E. (2009). Language characteristics of individuals with Down Syndrome. Language Disorders, 29, 112-132.

Moeller, M. P., Tomblin, J. B., Yoshinaga-Itano, C., Connor, C. M., \&Jerger, S. (2007).

Current state of knowledge: Language and literacy of children with hearing impairment. Ear and Hearing, 28, $740-753$.

Netten, A. P., Rieffe, C., Theunissen, S. C., Soede, W., Dirks, E., Korver, A. M. H., ...

Group, D. C. S. (2015). Early identification: Language skills and social functioning in deaf and hard of hearing preschool children. International Journal of Pediatric

Otorhinolaryngology, 79, 2221-6.

Rice, M. L., Tomblin, J. B., Hoffman, L., Richman, W. A., \& Marquis, J. (2004).

Grammatical tense deficits in children with SLI and nonspecific language impairment:

Relationships with nonverbal IQ over time. Journal of Speech, Language, Hearing Research, $47,816-834$.

Rice, M., \& Wexler, K. (1996).Toward tense as a clinical marker of specific language impairment in Englishspeakingchildren. Journal of Speech, Language, and Hearing Research, 39, 1239-1257.

Rice, M. L., Wexler, K., \& Hershberger, S. (1998). Tense over time: The longitudinal course of tense acquisition in children with specific language impairment. Journal of Speech, Language, Hearing Research, 41, 1412-1431.

Rutter, T. \& Buckley, S., (1994).The acquisition of grammatical morphemes in children with Down syndrome. DownSyndrome: Research and Practice, 2, 76-82. 
Sanz-Torrent, M., Serrat, E., Andreu, L. \& Serra, M. (2008). Verb morphology in Catalan and Spanish in children with specific language impairment: a developmental study. Journal of Clinical Linguistics \& Phonetics, 22 (6), 459-74.

Semel, E.,Wiig, E. \&Secord,W., (2006). Clinical Evaluation of Language Fundamentals: Fourth edition: CELF 4. London: Pearson Assessment (Harcourt Assessment).

Sepúlveda, E.M., López-Villaseñor, M.L., Heinze, E.G. (2013). Can individuals with Down syndrome improve their grammar? International Journal of Language and Communication Disorders, 48 (3), 343-349.

Tyler, A. A., Lewis, K. E., Haskill, A. \& Paul, K. (2003). Effects of a cycled morphological intervention on selected suppletive BE forms. Clinical Linguistics and Phonetics, 17 (1), 2542.

Ullman, M. T. \& Pierpont, E. I. (2005). Specific language impairment is not specific to language: the procedural deficit hypothesis. Cortex, 41, 399-433.

Vicari, S., Bellucci, S. \& Carlesimo, G.A. (2000). Implicit and explicit memory: a functional dissociation in persons with Down syndrome. Neuropsychologia, 38, 240-251.

Vicari, S., Caselli, M. C., \& Tonucci, F. (2000). Asynchrony of lexical and morphosyntactic development in children with Down syndrome. Neuropsycologia, 38, $634-644$.

Volterra, V., Caselli, M.C., Capirci, O., Tonucci, F., \& Vicari, S. (2003). Early linguistic abilities in Italian children with WS. Developmental Neuropsychology, 23, 33-58. 
Wang, P. P., \&Bellugi, U. (1994).Evidence from two genetic syndromes for dissociation between verbal and visual-spatial short-term memory.Journal of Clinical and Experimental Neuropsychology, 16, 317- 322.

World Health Organization (2011).World report on disability, 233-57.Available from http://www.who.int/disabilities/world_report/2011/en/.

Zwitserlood, R., Wijnen, F., van Weerdenburg, M., \&Verhoeven, L. (2015). 'MetaTaal': enhancing complex syntax in children with specific language impairment-a metalinguistic and multimodal approach. International Journal of Language \& Communication Disorders, $50(3), 273-297$. 


\section{Appendix A: Assessment of copula and auxiliary use}

Copula test items

Example: The cup is red

Trial 1: Your turn, tell me about this picture? Target: The car is red

Trial 2: (picture of a blue car) What about the one before? Target: The car was red Tell me about the colour...

1. The apple is green What about these?

2. The apples are green Here is a red apple. Can you remember the first apple?

3. The apple was green

4. Here are some more; these apples are red. Can you remember the other apples? The apples were green

Tell me about these fruits?

5. The banana and lemon are yellow Here is a black hat and black cup. Can you remember the banana and lemon?

6. The banana and lemon were yellow

Example: The cup is on the chair

Trial 1: Tell me about the cup Target: The cup is on the chair

1. The ball is on the table

2. The balls are on the table ( Picture of a cushion under the table) What about the ball?

3. The ball was on the table (Picture of cushions under the table) What about the balls?

4. The balls were on the table

5. The teddy and ball are on the table (hat and cushion under the table) What about the teddy and ball?

6. The teddy and ball were on the table

Auxiliary test items

Example: Here's a lady, what is she doing? The lady is drinking.

Trial: Now your turn, Tell me about this picture Target: The lady is eating

1. The dog is running

2. The man is sleeping

Blank screen: Tell me about the lady in the first picture?

3. The lady was drinking/eating 
And the man?

4. The man was sleeping

5. The babies are laughing

6. Dave* and Ahmed*are eating

7. Blank screen: Tell me about the children again? The children were playing

8. And what about Dave* and Ahmed*...

Dave /Ahmed /They were eating?

*pseudonyms for confidentiality 


\section{Appendix B: Intervention steps}

\begin{tabular}{|c|c|c|c|}
\hline Steps & Copula and Auxiliary interventions & Activity resources & Writing extension \\
\hline 1 & $\begin{array}{l}\text { Identifying the subject (who or } \\
\text { what) in the stimulus. }\end{array}$ & $\begin{array}{l}\text { Photos of objects in } \\
\text { different colours (blue, } \\
\text { red, yellow), and in } \\
\text { different positions (on, } \\
\text { under). For auxiliary } \\
\text { group: videos of simple } \\
\text { actions. }\end{array}$ & $\begin{array}{l}\text { Use Shape } \\
\text { Coding }{ }^{\mathrm{TM}} \text { 'oval' as } \\
\text { visual support }\end{array}$ \\
\hline 2 & $\begin{array}{l}\text { SLT/Pmodeling placement of one } \\
\text { red line under one Subject and two } \\
\text { red lines under more than one } \\
\text { Subject. Participants practice } \\
\text { counting subjects and underling } \\
\text { pictures with red lines, or in case of } \\
\text { video stimuli representing subjects } \\
\text { with red lines. }\end{array}$ & $\begin{array}{l}\text { Large laminated red } \\
\text { strips. } \\
\text { Large pictures of cat and } \\
\text { dog } \\
\text { Auxiliary group: videos } \\
\text { with more than one } \\
\text { subject }\end{array}$ & $\begin{array}{l}\text { Using red pens to } \\
\text { underline the } \\
\text { subjects }\end{array}$ \\
\hline 3 & $\begin{array}{l}\text { Introducing the diamond shapes } \\
\text { with 'is' and 'are' underlined with } \\
\text { blue lines. "Find the same number } \\
\text { of lines". "One red line goes with } \\
\text { one blue line". }\end{array}$ & $\begin{array}{l}\text { Shape coding }{ }^{\mathrm{TM}} \text { resource } \\
\text { of 'is' and 'are' in } \\
\text { diamond shape, with one } \\
\text { and two lines and middle } \\
\text { arrow (indicating present } \\
\text { tense) }\end{array}$ & \\
\hline 4 & $\begin{array}{l}\text { Finding the subject and counting, } \\
\text { placing red lines under and } \\
\text { matching with the correct diamond } \\
\text { shape. }\end{array}$ & $\begin{array}{l}\text { Pictures/photos/videos } \\
\text { and simple typed } \\
\text { sentences for readers }\end{array}$ & $\begin{array}{l}\text { Using red and blue } \\
\text { pens, making own } \\
\text { lines to match in an } \\
\text { empty diamond } \\
\text { shape }\end{array}$ \\
\hline 5 & $\begin{array}{l}\text { Introducing coordinated nouns and } \\
\text { applying red lines and matching } \\
\text { with blue line/s on copula in the } \\
\text { diamond. }\end{array}$ & $\begin{array}{l}\text { Pictures of different } \\
\text { people/objects }\end{array}$ & \\
\hline
\end{tabular}




\begin{tabular}{|c|c|c|c|}
\hline 6 & $\begin{array}{l}\text { Progression to tense marking: } \\
\text { highlighting the arrow on 'is' and } \\
\text { 'are' as present tense verbs. }\end{array}$ & Diamond shapes & Drawing arrows on \\
\hline 7 & $\begin{array}{l}\text { Identifying present tense temporal } \\
\text { concepts i.e. today, now and } \\
\text { placing middle arrows under these } \\
\text { words to match the middle arrows } \\
\text { under 'is' and 'are'. }\end{array}$ & $\begin{array}{l}\text { Signs and printed words: } \\
\text { today, now etc. }\end{array}$ & $\begin{array}{l}\text { Drawing arrows } \\
\text { under the middle of } \\
\text { the words }\end{array}$ \\
\hline 8 & $\begin{array}{l}\text { Introducing past tense temporal } \\
\text { concepts i.e. yesterday, last night, } \\
\text { and last week and placing left } \\
\text { arrows under these words. }\end{array}$ & $\begin{array}{l}\text { Signs and printed words: } \\
\text { yesterday, last night etc. } \\
\text { Auxiliary group: videos } \\
\text { of actions that took place } \\
\text { in the past }\end{array}$ & \\
\hline 9 & $\begin{array}{l}\text { Introducing diamond shapes 'was' } \\
\text { and 'were' and highlighting the left } \\
\text { arrows. Matching these with past } \\
\text { temporal adverbs. }\end{array}$ & $\begin{array}{l}\text { Diamonds with 'was' } \\
\text { and 'were' }\end{array}$ & $\begin{array}{l}\text { Drawing arrows } \\
\text { under the words to } \\
\text { the left }\end{array}$ \\
\hline 10 & $\begin{array}{l}\text { Identifying the subject and the } \\
\text { tense and making the accurate } \\
\text { plural agreement and then tense } \\
\text { agreement. }\end{array}$ & $\begin{array}{l}\text { Pictures/photos and } \\
\text { simple typed sentences } \\
\text { for readers }\end{array}$ & $\begin{array}{l}\text { Using red and blue } \\
\text { pens, making own } \\
\text { lines and arrows to } \\
\text { match in an empty } \\
\text { diamond shape }\end{array}$ \\
\hline 11 & $\begin{array}{l}\text { For writers, generalizing targets to } \\
\text { use lines and arrows to help self- } \\
\text { correct in their written work. }\end{array}$ & Red and blue pens & $\begin{array}{l}\text { Underlining } \\
\text { subjects with one } \\
\text { or two lines and } \\
\text { placing arrows } \\
\text { under temporal } \\
\text { adverbs }\end{array}$ \\
\hline
\end{tabular}

